\title{
A AUTORIDADE E A QUESTÃO DO PAI
}

\author{
Christian Hoffmann
}

Professor da

Universidade de

Poitiers,

psicanalista.

Tradução: Pedro

Henrique

Bernardes Rondon
RESUMO: A especificidade da abordagem psicanalítica da autoridade reside no fato de esta abordagem reconhecer a autoridade da palavra. Procura-se considerar, aqui, a autoridade da palavra em sua relação com o pai, à medida que a autoridade encontra seu fundamento inconsciente no significante da lei.

Palavras-chave: Autoridade, pai, lei.

ABSTRACT: The authority and the father issue. The specificity of the psychoanalytic approach to authority dwells on the fact that approach acknowledges the authority of the word. In this paper the author takes into account the authority of the word in its relation to the father, as the authority finds its unconscious foundation in the signifier of the law.

Keywords: Authority, father, law.

"A menos que levemos em consideração nossos quartos de criança e nossos lares, nosso comportamento para com os professores seria não apenas incompreensível, mas também indesculpável."

(Freud, 1914) ${ }^{1}$

$\boldsymbol{J}_{\mathrm{q}} \mathrm{og}$ ogo de saída poderíamos propor a nós mesmos a seguinte questão: o que é que a psicanálise sustenta como relação com a autoridade? Há uma filosofia da autoridade, uma sociologia, mas o que é que a psicanálise, a partir do lugar de seu exercício - o consultório do psicanalista — pode ter a dizer acerca da autoridade?

\footnotetext{
${ }^{1}$ Empregamos neste trabalho a Edição standard brasileira das obras psicológicas completas de Sigmund Freud, v. XIII, tradução de Órizon Carneiro Muniz. Rio de Janeiro: Imago, 1976. (N. do T.)
} 
Certa vez, assisti a um debate em que um jovem psicanalista pretendeu provocar um psicanalista mais velho atribuindo-lhe o qualificativo de anarquista. Certamente não, retrucou este último, referindo-se àquilo que constitui a essência da prática psicanalítica, isto é, a autoridade da palavra.

É preciso, portanto, que abordemos a autoridade sob sua forma psicanalítica específica que é a autoridade da palavra.

Para isso, vou partir de um exemplo que me foi relatado por um jovem colega psicólogo que trabalha como conciliador ${ }^{2}$ nos transportes urbanos. Ele me relatou que se viu desafiado ante uma situação de violência coletiva entre jovens dentro de um ônibus. Inquieto, ele se espantou com aquilo que veio em seu socorro, e que parecia das coisas mais inacreditáveis. O que aconteceu? No auge da agitação, a escalada da violência estancou de repente quando o ônibus parou num ponto e um jovem disse: “Tem um pai ali na calçada.” De fato, havia um homem adulto, de cerca de 50 anos, de pé, na calçada. O homem não disse uma única palavra, mas sua simples presença apagou o incêndio da violência.

O que poderíamos extrair como ensinamento desse exemplo, senão que a simples evocação do pai, reduzido à sua expressão mais simbólica - isto é, o nome de pai —, no que esse nome tem uma autoridade, permitiu a extinção do fogo da violência.

Eis aí aquilo que precisamos tentar esclarecer a partir da psicanálise: a autoridade da palavra e sua relação com o pai.

Ocupemos um pouco de nosso tempo examinando aquilo que a filosofia da autoridade nos ensina, na escritura de Kojève - hegeliano e mestre de Jacques Lacan, Georges Bataille e tantos outros. Em sua obra de 1942, intitulada La notion de l'autorité (KOJÈVE, 1942/2004), redigida imediatamente antes de L'esquisse d'une phénoménologie du droit, Kojève distingue quatro tipos irredutíveis de Autoridade: a do Pai (fundada na Causa), a do Mestre (fundada no Risco), a do Chefe (fundada nos Projetos e nas previsões) e a do Juiz (fundada na eqüidade e na justiça). Ele estabelece a correspondência entre esses quatro tipos de autoridade e quatro filosofias, respectivamente a Escolástica, Hegel, Aristóteles e Platão.

$A$ autoridade do Pai (ou dos pais, em geral) sobre a criança tem como variantes as autoridades dos mais velhos, da tradição, do autor, do morto, etc.

Kojève logo define em nota sobre $A$ autoridade do morto:

"De maneira geral, o homem tem mais Autoridade após sua morte do que em vida: o testamento tem mais Autoridade do que a ordem dada pelo homem enquanto está vivo; uma promessa prende mais depois da morte daquele a quem foi feita, as ordens

\footnotetext{
${ }^{2}$ O conciliador é alguém que, na França, representa a empresa nas disputas com sindicatos de profissionais dos transportes. [N. da T.]
} 
do pai morto são mais respeitadas do que aquelas que ele dava enquanto vivia, etc. A razão para isso é que é materialmente impossível reagir contra um morto. Tem, portanto, autoridade por definição. Mas essa impossibilidade de reação garante à Autoridade do morto um caráter divino (sagrado): o exercício da Autoridade pela morte não comporta nenhum risco para ele. Donde, a força e a fraqueza dessa autoridade. No final das contas, é um caso particular de autoridade divina." (KOJÈVE, 1942/2004, p. 67-68)

Podemos, em primeiro lugar, apreender aí a definição de Kojève, dentro de um enquadramento fenomenológico, da autoridade como ação que não provoca reação. Isso levanta a questão de saber por que essa renúncia é o reconhecimento da autoridade, e se sem esse reconhecimento não existiria autoridade. Em suma, a autoridade pressupõe seu reconhecimento e o recalcamento da reação, que sempre será possível.

Kojève toma o cuidado de distinguir a autoridade do morto da do Mestre. A autoridade do Mestre sobre o Escravo nasce na luta de morte pelo reconhecimento. Nessa luta, o Mestre arrisca sua vida, uma vez que o escravo se inclina porque não chega a dominar seu temor da morte. A teoria de Hegel, para Kojève, é uma teoria da autoridade do Mestre, fundada sobre o Risco. Em contrapartida, a Autoridade do Chefe lhe vem do fato de que se supõe que ele está adiante dos outros, supõe-se que ele veja melhor do que os discípulos, segundo a teoria do Aristóteles. Para a autoridade do Juiz, segundo Platão, esta é sui generis, e Kojève subscreve isso.

É preciso que voltemos agora à autoridade do pai, uma vez que esta "não tem nada a ver com seu valor pessoal”, Kojève (idem, p. 76) nos diz, muito acertadamente, sendo o caso contrário para o Chefe.

Não se trata de que, diz Kojève, na Autoridade do Pai:

\footnotetext{
“A noção de hereditariedade intervenha naturalmente: essa autoridade se funda na relação entre pais e filhos; é natural admitir que a Autoridade do Pai passa - como uma herança - para o Filho (uma vez que este se torne Pai por sua vez, e [que] seu próprio pai morra)." (idem, p. 81)
}

Antes de examinar a relação da autoridade com o pai morto, que insiste em Kojève, é preciso que eu introduza um ponto de atualidade. A circularidade hegeliana que vai do real — aqui, a natureza - ao racional (o Direito natural, por exemplo) e do racional ao real, é interrompida pela evolução técnico-científica e pela mutação da norma social, notadamente a da família, uma vez que o Édipo não é mais a norma social universal. A psicanálise de Lacan a Freud já antecipava essa verdade ao mostrar que, na família, o Pai (com P maiúsculo) não é o genitor (LACAN, 1974, p.51).

Resta a questão do fundamento da autoridade no pai morto. 
Tive que me ocupar de um menino que acabara de perder o pai e que, desde então, tinha se refugiado no leito materno, onde era presa de terríveis pesadelos de devoração. Bastou que ele pudesse se aperceber da permanência simbólica do pai, por meio do reconhecimento de seu amor, para que pudesse reencontrar seu lugar certo em seu próprio quarto.

Outro exemplo é o de um menino que, escapando à vigilância do pai que o levara à cabeceira de seu avô morto, encheu várias folhas de papel com o nome de seu avô, batucando compulsivamente em sua escrivaninha.

Em suma, o pai morto se inscreve em seu nome, o qual lhe garante uma permanência simbólica, donde a força que tem. Mas que força é essa? A resposta já está ao alcance de nossas mãos: não há força maior do que aquela de garantir a presença de uma autoridade, mesmo estando ausente. O que nos dá a definição de símbolo que é feito de presença/ausência.

Deixemos que esse assunto seja esclarecido por um menino que, ao voltar da escola, se refugiava na banheira durante horas. Logo fiquei sabendo que, na ausência do pai, durante a semana, toda a pequena família dividia a cama da mãe, sem que o pai tivesse sido informado disso. Aliás, o pai é o digno sucessor de uma empresa familiar internacionalmente conhecida por seu nome, líder na venda de aparelhos sanitários e, conseqüentemente, de banheiras. Não é preciso muito esforço para compreender que a banheira é o símbolo paterno na família, o que garante a permanência do limite ao gozo, especialmente materno, isto é, o interdito do incesto.

Há, portanto, a autoridade do símbolo que garante a permanência do interdito. Moustapha Safouan esclarece-nos de maneira incomparável acerca da estruturação do limite no ser humano, e suas incidências sociais num mundo que hoje em dia alguns qualificam como 'sem limites'. O que pressupõe que estejamos em condições de definir psiquicamente o limite.

A criança, diz-nos M. Safouan, experiencia em sua ligação com a mãe que 0 amor materno não é infinito. Como? Experienciando o nome que limita o amor materno, separando sexualidade e ternura. Dessa incompletude do amor materno, produzse uma significação a que chamamos fálica.

A criança se vê excluída dessa parte sexuada do amor da mãe, essa parte que constitui o objeto do desejo da mãe, e que esta vai procurar satisfazer com um homem. Se a criança não é o objeto do desejo de sua mãe que tem um desejo em outro lugar, então a criança viverá a si mesma como falta a ser esse objeto do desejo de sua mãe: é este objeto que chamamos falo. Donde a produção da significação fálica de querer ser aquilo que lhe falta para ser esse objeto do desejo da mãe, e que a criança vê aparecer no homem da mãe. Assim, ante o anúncio da chegada de uma outra criança na família, uma menininha disse aos seus pais: “Então eu não sou mais suficiente para vocês?" 
Essa busca fálica pode se transformar em verdadeira paixão do ser; principalmente na adolescência, pois, como sabemos, essa busca pode assumir uma aparência trágica, em que o destino é lançado entre ser (o falo), ou a morte. Um ser humano pode preferir a morte à perda de sua identificação fálica narcísica.

Recebi um caso assim numa emergência: uma adolescente queria se suicidar porque sua amiga a traíra com outra. O mesmo aconteceu com um garoto cuja namorada acabara de ir embora com seu melhor amigo, e que me dizia: "se isso é possível, então a vida não vale a pena ser vivida”.

Ouvimos igualmente versões menos trágicas, como uma interna de medicina que queria ser perfeita e desmoronou à mínima crítica do chefe.

De onde vem essa questão de algo que pode acabar com essa posição 'paranóide' de ser ou não ser o falo? Quem pode dizer 'não', e fazer cessar essa corrida louca? Quem tem autoridade para isso? Safouan indica que é esta função normalizante que cabe a esse que é reconhecido como pai na família. É ele que tem a autoridade, essa autoridade que se apóia no significante da lei, e que dá legitimidade ao seu ato de dizer que 'não' a essa busca do ser.

Temos agora a nossa disposição uma teoria do limite cujo fundamento inconsciente repousa sobre o significante da lei, daquela que está inscrita no nome.

Agora me expliquem: como um significante pode ter autoridade? Entretanto, a experiência humana demonstra isso dia a dia. Se eu chamo um nome, há forte possibilidade de que alguém se levante para responder. Se, além disso, eu digo: você é parente de fulano ou de sicrana, que tem o mesmo nome que você? Constato então que o nome leva com ele a inscrição do parentesco e da filiação. Fica fácil perceber que o nome é o portador da autoridade do interdito do incesto.

Foi o que Lacan, seguindo Freud e os antropólogos, condensou em sua teoria da metáfora paterna:

\footnotetext{
“Não há, é claro, nenhuma necessidade de um significante para ser pai, não mais do que para estar morto, mas sem o significante ninguém, nem de um nem de outro desses estados do ser, nunca poderá nada (...) o pai simbólico, uma vez que significa essa lei [do interdito] é bem o Pai morto.” (LACAN, 1966, p.556)
}

Podemos agora voltar ao nosso ponto de partida com Kojève acerca da autoridade do Pai morto. Alguém como Schiller já pôs na boca de um de seus personagens paternos, dirigindo-se ao seu herdeiro, para moderar seu entusiasmo: "Quando eu for apenas o meu nome." O ser pode se reduzir ao nome e representar a autoridade na cadeia das gerações.

Certo dia, recebi uma mulher, mãe de uma adolescente que fugira de casa e passara dois anos sem dar notícias. Ela reapareceu grávida, pedindo à mãe que a aceitasse e a ajudasse a criar seu filho. Tomada de angústia diante de tal pedido, 
ela veio me procurar como terceiro, para me dizer o que tinha 'ouvido' nesse pedido: sua filha estava lhe trazendo agora a criança que lhe pedira quando era pequena. Essa mulher só podia dizer não ao gozo de sua filha re-dirigindo sua demanda para um terceiro.

Vou agora tratar do que evoquei a propósito do fundamento inconsciente da autoridade. Para isso, vou tomar um exemplo da minha prática clínica.

A adolescência é o tempo da redistribuição subjetiva das coordenadas psicológicas do sujeito. Assim, tratava-se de um jovem adolescente que se entregara à delinqüência e por fim se identificara com os jovens para os quais, como se diz habitualmente, mais nenhuma palavra tem autoridade. O que teria acontecido a ele de tão decisivo, entre uma infância mais calma e uma adolescência retumbante? Como costuma acontecer, este garoto que era "o homenzinho da sua mãe”, ajudando-a em todas as suas tarefas, até na educação de seus meio-irmãos e irmãs, enfiou na cabeça, ao chegar à adolescência, que devia perguntar à mãe para descobrir quem era seu pai. A resposta da mãe era o reflexo exato de sua história: "Basta você se olhar no espelho." Em seguida, ele me contou que sua mãe não lhe dera nem o nome, nem mesmo uma fotografia do pai. A partir dessa resposta, ele mergulhou na delinqüência, a começar pelas discussões cada vez mais violentas com os homens que passavam pela casa. Ele não conseguia mais reconhecer nesses homens qualquer autoridade sobre si. Toda forma de autoridade se perdia, resvalando nele como a água nas penas do pato.

Temos aí um exemplo de forclusão do nome do pai e, conseqüentemente, do fundamento inconsciente da autoridade. Essa história confirma totalmente aquilo que se pode extrair das palavras da mãe. Se a imagem no espelho provoca a confusão entre o modelo e a cópia, então não há mais possibilidade, para o menino, de estabelecer uma relação pai-filho baseada no modelo inconsciente pelo exemplo da semelhança, como se costuma dizer: ele é o retrato do pai, uma vez que tal semelhança pode se basear apenas em seu caráter. Mais do que uma impossibilidade, trata-se, aqui, de uma forclusão do significante da autoridade. Em conseqüência disso, especialmente na adolescência, nenhuma autoridade será legítima, talvez apenas a do Super-homem.

Tudo se passa de maneira completamente diferente para uma criança como A. Camus, que foi criado pela mãe e pela avó, na ausência do pai que morrera na guerra. Sua mãe não podia falar com ele sobre o pai, porque não conseguia conter sua dor. Na adolescência, ele dizia sentir-se perdido, tendo consciência de que precisaria de um guia, de uma autoridade que ele distinguisse do poder. Sabemos o que aconteceu depois: um Mestre lhe estendeu a mão - e foi o Prêmio Nobel. Na noite de sua recepção em Oslo, ele escreveu ao sr. Germain: "Sem o senhor, sem aquela mão estendida ao pobre menininho, eu não seria nada, nada...", e ele respondeu: Meu filho... Enfim, a transferência. 
Temos agora uma definição de autoridade fundada no inconsciente sobre a lei do interdito do incesto do qual, como diz Freud, manifestamente o pai "é o representante" (FREUD, 1924, p.352). Ele acrescenta que na análise sempre se encontra “o pai como o portador do interdito". De onde, então, vem o interdito? Conhecemos a resposta de Lacan: é a mãe quem introduz a criança numa ordem simbólica na qual o limite ao gozo é aplicado primeiramente a ela, depois à criança. O pai intervirá aí como produto da metáfora do nome que significa a lei.

É claro que há mais do que um significante da lei possível para um sujeito humano. Por exemplo, o temor a Deus na Athalie de Racine é um significante da autoridade.

E o pai real, que é quem importa nessa operação simbólica, o que é feito de sua vontade? Quando aponta sua referência para esse terceiro paterno entre ela e a criança, de certa maneira a mãe o está designando Senhor do desejo, aquele que dominou a castração, aquele que a psicanálise reconhece como o pai ideal.

A esse propósito temos um bonito texto de Freud à nossa disposição. Trata-se de um artigo de 1914, "Sur la psychologie du lycéen" (FREUD, 1914/1988). ${ }^{3}$ Notemos de passagem que os maiores textos sobre a autoridade foram redigidos durante os períodos de barbárie da nossa história: Kojève, Russel, Freud, Arendt.

Esse texto de Freud contém o essencial de uma psicanálise do adolescente. Freud procura esclarecer aí nossa ambivalência ante nossos professores, conforme o modelo freudiano da repetição, nas nossas relações atuais, de traços mnésicos das nossas primeiras relações infantis com os pais, com a fratria, e algumas outras de nossa infância. Não há dúvida quanto a que a relação com o pai é em larga medida a mais tingida de ambivalência. Na segunda metade da infância, nos diz Freud, é que intervém uma mudança “cuja importância não se poderia subestimar" e que passo a citar:

\footnotetext{
“De seu quarto de criança, o menino começa a vislumbrar o mundo exterior e não pode deixar de fazer descobertas que solapam a alta opinião original que tinha sobre o pai e que apressam o desligamento do seu primeiro ideal. Descobre que o pai não é mais o mais poderoso, mais sábio e mais rico dos seres, fica insatisfeito com ele, aprende a criticá-lo, a avaliar o seu lugar na sociedade; e então, em regra, faz com que ele pague pesadamente pelo desapontamento que lhe causou. Tudo o que há de admirável e de indesejável na nova geração é determinado por esse desligamento do pai." (FREUD, 1914/1988, p.268)
}

Freud acrescenta que é nesse momento que ocorre o encontro com os professores que se tornam para nós “um substituto paterno”. Transferimos para eles o

\footnotetext{
3 “Algumas reflexões sobre a psicologia do escolar”. ESB, v.XIII.
} 
respeito, diz Freud, e isso me permite compreender a afirmação de Moustapha Safouan, que fez da ausência de respeito um signo de inquietação quanto à subjetividade.

O professor é um substituto paterno, herdeiro do "pai onisciente de nossos anos de infância”. O chefe vem no lugar desse ideal, realizando-o ao título de “substituto de uso coletivo". Basta então projetar uma causa comum para que cada um dos membros do grupo possa encontrar aí um desejo que dá um sentido à vida, pronto a sacrificá-la para sustentar o ideal.

O que me dá a oportunidade de concluir pelo final da obra de Freud acerca da questão do assassinato de Moisés. Aquilo que chamamos de assassinato do pai tem como objetivo apenas romper o mármore do Pai ideal, esse super-homem, aquele que para a criança é suposto ser o senhor do desejo e que dessa maneira se torna o estilo de sua busca fálica. Trata-se de quebrar esse mármore da servidão voluntária para encontrar, com o nome do pai, o símbolo da presença/ausência que articula a lei do nome ao desejo, um desejo que não é mais um desejo de ser aquilo que falta, nem tampouco o de servir ao pai. Em suma, um desejo menos atrapalhado pela servidão do ideal e mais espinozista em sua essência.

Teremos compreendido isso. Servir-se do símbolo do pai para escolher o objeto do nosso desejo é bem diferente de servir seu mármore como penhor de seu gozo.

Toda a obra de alguém como Racine está aí para nos dar a entender o que há de trágico entre a lei do nome e o gozo do cetro.

Recebido em 17/4/2006. Aprovado em 15/5/2006.

\section{REFERÊNCIAS}

FREUD, S. (1914/1988) “Sur la psychologie du lycéen”, in Résultats, idées, problèmes, T. 1. Paris: PUF. [No Brasil: "Algumas reflexões sobre a psicologia do escolar”, in Edição standard das obras psicológicas completas de S. Freud, v.XIII.Tradução de Órizon Carneiro Muniz. Rio de Janeiro: Imago, 1976. (N. do T.)].

(1924) Correspondance avec Karl Abraham. Paris: Gallimard.

KOJÈVE, A. (1942/ 2004) La notion de l'autorité. Paris: Gallimard.

LACAN, J. (1966) Écrits. Paris: Seuil. . (1974) Télévision. Paris: Seuil.

Christian Hoffmann

hoffmann.ch@wanadoo.fr 